\title{
"Companheiros de infortúnio": a educação de "surdos-mudos" e o repetidor Flausino da Gama
}

CÁSSIA GECIAUSKAS SOFIATO

Pontifícia Universidade Católica de Campinas

LUCIA HELENA REILY

Universidade Estadual de Campinas

\section{INTRODUÇÃO}

Este estudo tem como objetivo apresentar a trajetória educacional de Flausino José da Costa Gama, surdo "repetidor", figura importante para a constituição da língua brasileira de sinais por intermédio de sua produção: a Iconographia dos Signaes dos Surdos-Mudos, de 1875. Além disso, destacar como era realizada a educação dos surdos no Imperial Instituto dos Surdos-Mudos no século XIX, especificamente no período em que Flausino atuou nesse espaço, de 1869 a 1878.

A Iconographia dos Signaes dos Surdos-Mudos foi uma obra muito relevante na história da surdez e da língua de sinais no Brasil, entretanto, para este estudo, o recorte será a educação do surdo e o papel do repetidor Flausino no Imperial Instituto dos Surdos-Mudos.

\section{PERCURSO METODOLÓGICO}

O presente estudo caracteriza-se por ser uma pesquisa bibliográfica e documental. Gil (1991) aponta que a pesquisa bibliográfica muito se assemelha à pesquisa documental, porém a diferença essencial entre elas é a natureza das fontes. $\mathrm{Na}$ pesquisa documental, utilizam-se materiais que ainda não sofreram um trata- 
mento analítico ou que ainda podem ser redimensionados dependendo do objeto de pesquisa. Neste trabalho, a busca de fontes primárias foi algo bastante valorizado e necessário para a elucidação dos fatos históricos.

Num primeiro momento, recorremos à literatura já existente para construir um contexto a partir do qual pudéssemos aprofundar as questões propostas para este estudo. Paralelamente, fomos utilizando fontes primárias, constituídas basicamente de documentos e relatórios da época do Brasil Império, que nos auxiliaram na construção de um referencial teórico basilar para a compreensão desse período histórico e das circunstâncias em que se deu a constituição de nosso objeto de estudo. Os documentos da época do Império consultados encontram-se na base de dados Center for Research Libraries - Almanak Laemmert (1844-1889). Os dois relatórios consultados foram escritos pelo Dr. Tobias Leite, diretor do Imperial Instituto dos Surdos-Mudos, e datam de 1869 e 1871; foram conseguidos por ocasião de uma visita ao Instituto Nacional de Educação de Surdos no Rio de Janeiro.

\section{PARTICULARIDADES DO IMPERIAL INSTITUTO DOS SURDOS-MUDOS}

A história da educação dos surdos no Brasil inaugura-se em 1857 com a fundação do Imperial Instituto dos Surdos-Mudos no Rio de Janeiro (Jannuzzi, 2004). $\mathrm{O}$ primeiro diretor foi E. Huet, cuja gestão não analisaremos, pois nosso estudo trata de um período posterior. Após a saída de Huet, em 1861 (Rocha, 2007), o Instituto foi administrado por três diretores que não ocuparam por muito tempo essa função, à exceção de Manoel de Magalhães Couto, que assumiu o cargo em 1862. Nesse ínterim, o Instituto ganhou um regulamento provisório que definiu seu quadro de funcionários da seguinte maneira: "um diretor, um professor, uma professora, um capelão, um inspetor de alunos, uma inspetora de alunas, um roupeiro, uma enfermeira, uma despenseira, uma criada, um cozinheiro e quatro serventes" (Rocha, 2007, p. 35).

O regulamento provisório também apresentava aspectos relativos à educação de surdos, entre eles o item ensino, para o qual foram designadas as seguintes disciplinas: "Leitura Escrita, Doutrina Cristã, Aritmética, Geografia com ênfase no Brasil, Geometria Elementar, Desenho Linear, Elementos de História, Português, Francês e Contabilidade" (idem, ibidem, grifo nosso).

Em 1868, o chefe da Seção da Secretaria de Estado, Dr. Tobias Leite, foi nomeado para fazer um relatório sobre as condições de funcionamento do Instituto. Constatou que na instituição não havia ensino e sim uma casa que servia de asilo aos surdos. Dessa forma, o então diretor, Manoel de Magalhães Couto, foi exonerado e, em seu lugar, quem assumiu interinamente a direção do Instituto foi o próprio Tobias Leite. De acordo com Soares (1999), Tobias Leite foi o quarto diretor do Instituto. Assumiu a interinidade de 1868 a 1872 e, a partir daí, foi diretor efetivo até 1896 , ano de sua morte. 
É interessante destacar que o diretor Tobias Leite, apesar de todos os intentos de favorecer a educação dos surdos que chegassem ao Instituto, tinha as suas convicções em relação aos objetivos dos estabelecimentos que se dedicavam a esse tipo de trabalho:

O fim dos Institutos dos surdos-mudos não é formar homens de letras, como parece ter sido o pensamento do Regulamento n. 4.046 de 19 de dezembro de 1867; o fim único destes estabelecimentos é arrancar do isolamento, que embrutece, os infelizes privados do instrumento essencial para a manutenção e desenvolvimento das relações sociaes; é emfim converter em cidadãos úteis indivíduos que the pesão, e a damnificão involuntariamente. (Leite, 1869, p. 4)

Esse pensamento do diretor Tobias Leite não era muito diferente daquilo que se pretendia por ocasião da fundação do Instituto, divulgado à população em geral por meio do Almanak Laemmert:

Regenerar uma classe inteira de seres desgraçados muito tempo abandonados, pô-los na posse de uma instrucção impossível de adquirir de qualquer outro modo, por meio de methodo especial, restitui-los á sociedade, á sua família, e pô-los em estado de poderem um dia dirigir seus próprios negócios - tal tem sido o fim da fundação do estabelecimento. (Almanak Laemmert, 1859, p. 478)

Considerando o contexto histórico, nosso foco recai sobre a atuação de Flausino no Imperial Instituto dos Surdos-Mudos.

\section{FLAUSINO DA GAMA: CRIADOR E REPETIDOR DE UMA TRADIÇÃO ICONOGRÁFICA}

Entre os muitos alunos que passaram pelo Imperial Instituto dos Surdos-Mudos, um deles ocupou um papel de destaque: Flausino José da Costa Gama. É necessário assinalar a escassez de dados biográficos sobre Flausino da Gama. Apesar de se apresentar como um aluno de destaque, existem pouquíssimas fontes bibliográficas e documentais que trazem dados sobre a sua vida. Evidenciou-se não somente pelo seu notável desempenho acadêmico, mas também pelo seu papel na elaboração da obra considerada a primeira de língua brasileira de sinais: Iconographia dos Signaes dos Surdos-Mudos.

Consta no documento intitulado "Alumnos do Instituto dos Surdos-Mudos", escrito pelo então diretor Tobias Leite, datado de 5 de abril de 1870, que Flausino ingressou no Imperial Instituto dos Surdos-Mudos em primeiro de julho de 1869, aos 18 anos. Filho legítimo de Anacleto José da Costa Gama, era surdo congênito e pensionista do Estado. $\mathrm{O}$ documento destacava sua magreza e abundante inteligência. Um fato que nos chama a atenção é a idade que Flausino apresentava 
quando ingressou no Instituto. Seus colegas eram mais novos; segundo a mesma fonte, tinham entre 9 e 15 anos. Não sabemos precisar por que ele foi aceito se não atendia aos critérios de faixa etária estabelecidos para a matrícula no Instituto. Ao todo, no ano de 1870, o Instituto tinha 13 alunos, incluindo Flausino.

O Imperial Instituto dos Surdos-Mudos inspirava-se numa tendência que vinha do Instituto Nacional de Surdos de Paris, que era a de ter seus ex-alunos atuando como professores. O professor repetidor tinha muitas funções dentro do Instituto. Como refere Rocha (2007), o repetidor tinha de assistir à aula e depois repetir as lições do professor aos alunos que tinha sob a sua responsabilidade. Também era de sua incumbência o acompanhamento dos alunos no recreio e o seu retorno à sala de aula. Além disso, acompanhava os visitantes do Instituto, pernoitava com os outros alunos, corrigia os exercícios dados pelo professor e fazia a sua substituição quando necessário. Quanto à sua nomeação, esta ocorria se mostrasse conhecimento e capacidade na disciplina escolhida para tal designação. Dessa forma, cada disciplina tinha o seu repetidor. Essa atribuição de repetidor remete-nos à atuação dos alunos no Método de Lancaster. ${ }^{1}$ Consta que essa função foi modificando-se em razão de alterações regimentais, e que nos primeiros anos do Instituto era exercida por alunos. De acordo com as informações contidas no Almanak Laemmert, Flausino iniciou o seu trabalho de repetidor em 1871, aos 20 anos, e teria encerrado suas atividades em 1878, aos 27 anos de idade.

De acordo com os relatos do diretor Tobias Leite, no ano de 1871, o trabalho do Instituto teve um diferencial:

A instrução progrediu satisfatoriamente no ultimo anno. Concorreu para isso não só a prática, que vão tendo os Professores, mas o terem tido os alumnos como Repetidor de suas lições o ex-alumno Flausino José da Gama, que manifestou as melhores condições para o professorado. (Leite, 1871, p. 5)

Verificamos a importância que teve o aluno Flausino para o Instituto, e quanto ele era apreciado pelo diretor Tobias Leite. Entretanto, um fato chama-nos a atenção: Flausino ingressou no Imperial Instituto em 1869, aos 18 anos. Dois anos após, tornou-se um repetidor. É surpreendente que, em tão pouco tempo, Flausino tenha se destacado tanto a ponto de ocupar esse cargo e servir de exemplo aos seus companheiros de causa e, inclusive, à sociedade da época. Isso nos leva a pensar na

1 O Método de Lancaster ou Método Lancasteriano foi iniciado pelo inglês Joseph Lancaster, em 1798, quando estabeleceu em um subúrbio londrino uma escola para os filhos da classe trabalhadora, utilizando monitores para o desenvolvimento das atividades pedagógicas. De acordo com Neves (2003), "Lancaster amparou seu método no ensino oral, no uso refinado da repetição e, principalmente, na memorização, porque acreditava que essa inibia a preguiça, a ociosidade, e aumentava o desejo pela quietude”. Segundo a autora, para Lancaster os monitores eram responsáveis por várias tarefas, entre elas: a organização geral da escola, a limpeza, e principalmente a manutenção geral da ordem, tarefa relevante do monitor lancasteriano. 
possibilidade de Flausino ter cursado outro colégio antes de ingressar no Instituto e não ser tão neófito assim em conhecimentos acadêmicos; ou, talvez, os fatos narrados não tenham acontecido na realidade da forma como foram descritos.

O Almanak Laemmert, por meio de sua produção anual, possibilita-nos uma ideia de como se deu a atuação de Flausino enquanto repetidor, constituindo assim uma "série histórica", da qual incluímos um exemplo:

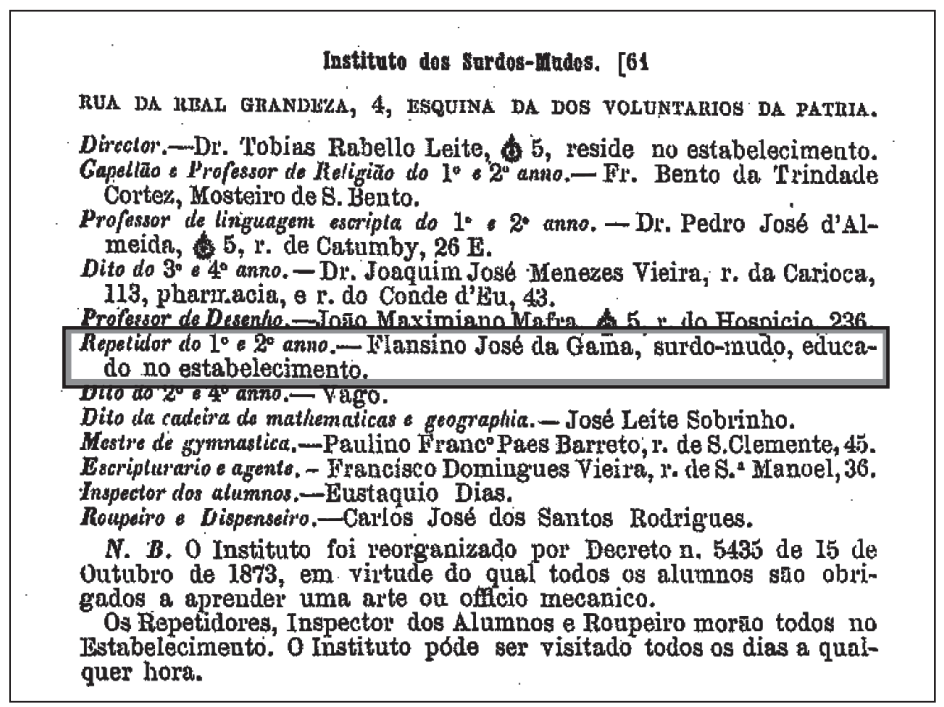

Figura 1: Página do Almanak Laemmert.

Fonte: Almanak Laemmert, 1874, p. 103.

O diretor Tobias Leite demonstrava orgulho pela atuação de Flausino no Instituto:

A nomeação desse repetidor não foi só pela satisfação de uma das mais vitaes necessidades do Instituto, foi também um acto fecundo de bons resultados para os alumnos, que animaram-se e regozijaram com as lições de um companheiro de infortúnio, e para o publico, que, vendo um surdo-mudo educado n'este Instituto exercer as funções de Professor, tem a maior prova de proficuidade do ensino. (Leite, 1871, p. 5)

Esse elogio revela-nos que o diretor valorizava a atuação dos repetidores, e que ter um surdo de destaque no Instituto era importante porque, ao mesmo tempo em que supria a falta de docentes, servia de exemplo para outros surdos. Além disso, era uma maneira de mostrar à sociedade da época que o ensino oferecido no Instituto era de qualidade. Podemos observar nos relatórios de Tobias Leite uma preocupação em declarar os gastos ao Estado, visto que este destinava uma subvenção especial na lei do orçamento para a manutenção do Instituto. 


\section{CONTEÚDOS CURRICULARES À ÉPOCA DE FLAUSINO DA GAMA}

O diretor Tobias Leite defendia que fosse ensinada ao surdo uma linguagem que possibilitasse sua relação com a sociedade. Essa linguagem poderia ser escrita ou vocal artificial. ${ }^{2}$ Leite (1869) declara que o regulamento n. 4046 "aglomerou" o ensino de ambas as linguagens, parecendo dar mais ênfase à vocal artificial. Convém assinalar que o ensino da linguagem escrita era obrigatório para todos os alunos, e que o ensino da linguagem falada era prevista para os surdos que tivessem adquirido a surdez após o nascimento e aos poucos surdos congênitos que fossem susceptíveis a ela, ou seja, que tivessem condições de adquiri-la. Para que isso fosse possível, o Instituto do Rio de Janeiro inspirava-se no trabalho desenvolvido no Instituto Nacional de Surdos-Mudos de Paris, embora o programa de estudos destinados aos surdos do Instituto Imperial dos Surdos-Mudos fosse mais elementar a princípio (conferir quadro 1):

\section{Quadro 1 - Relação entre os Currículos do Instituto Nacional de Surdos de Paris e do Imperial Instituto dos Surdos-Mudos (Rio de Janeiro)}

\begin{tabular}{|c|ll|}
\hline Anno & Instituto de Pariz & Instituto do Rio de Janeiro \\
\hline $\mathbf{1}^{\mathbf{0}}$ anno & Linguagem escripta, linguagem fallada & $\begin{array}{l}\text { Articulação artificial, leitura sobre os } \\
\text { lábios, leitura escripta, as quatro espécies e } \\
\text { doutrina christã }\end{array}$ \\
\hline $\mathbf{2}^{\mathbf{0}}$ anno & $\begin{array}{l}\text { Linguagem escripta, linguagem fallada, } \\
\text { sommar e diminuir }\end{array}$ & $\begin{array}{l}\text { Leitura, escripta, arithmetica, grammatica } \\
\text { portugueza e historia sagrada }\end{array}$ \\
\hline $\mathbf{3}^{\mathbf{0}}$ anno & $\begin{array}{l}\text { Linguagem escripta, linguagem fallada, } \\
\text { historia sagrada, multiplicar e repartir }\end{array}$ & $\begin{array}{l}\text { Portuguez, arithmetica, pesos e medidas, } \\
\text { geometria elementar e desenho linear }\end{array}$ \\
\hline $\mathbf{4}^{\mathbf{0}}$ anno & $\begin{array}{l}\text { Linguagem escripta, linguagem fallada, } \\
\text { historia sagrada, fracções }\end{array}$ & $\begin{array}{l}\text { Arithmetica, elementos de historia, } \\
\text { geographia, portuguez e francez }\end{array}$ \\
\hline $\mathbf{5}^{\mathbf{0}}$ anno & $\begin{array}{l}\text { Linguagem escripta, linguagem fallada, } \\
\text { historia e geographia, decimaes }\end{array}$ & $\begin{array}{l}\text { Continuação de historia e geographia, } \\
\text { portuguez, francez e desenho }\end{array}$ \\
\hline $\mathbf{6}^{\mathbf{0}}$ anno & $\begin{array}{l}\text { Linguagem escripta, linguagem fallada, } \\
\text { historia e geographia, proporções }\end{array}$ & \\
\hline $\mathbf{7}^{\mathbf{0}}$ anno & $\begin{array}{l}\text { Linguagem escripta, linguagem fallada, } \\
\text { historia e geographia, complexos }\end{array}$ \\
\hline & $\begin{array}{l}\text { Curso Superior- Grammatica franceza, } \\
\text { historia, geographia, arithmetica, álgebra, } \\
\text { geometria e direito commum }\end{array}$ \\
\hline
\end{tabular}

Fonte: Instituto dos Surdos-Mudos. Relatório do director. Tobias Leite, 1869.

O diretor Tobias Leite, em seu relatório de 1871, endereçado ao senhor conselheiro João Alfredo Corrêa de Oliveira, então ministro e secretário de Estado dos Negócios do Império, destaca as suas concepções sobre o ensino religioso e a

2 A linguagem "vocal artificial” seria a linguagem oral adquirida por meio de métodos específicos utilizados na educação de surdos. 
educação moral, considerados também "conteúdos" intrínsecos à formação que o Instituto se dignava a oferecer aos surdos que ali ingressassem.

Leite (1871, p. 6) considerava que "o sentimento religioso é innato ao surdo-mudo que o manifesta por signaes tão expressivos, que não deixam duvida”. Para que esse "sentimento" fosse melhor desenvolvido eram oferecidas no currículo no $1^{\circ}$ e 2o anos a "Doutrina Christã" e a "História Sagrada”, respectivamente. É inegável a influência do cristianismo nesse período nos colégios de maneira geral. Para elucidar essa influência, selecionamos algumas menções na propaganda de alguns colégios na época do Império. O Collegio Brasileiro para Educação de Meninas, dirigido por D. Florinda de Oliveira Fernandes, por exemplo, fazia o seguinte destaque sobre o ensino religioso:

Em todos os domingos e dias santos há missa na capella do collegio. Nesses dias e nas quintas-feiras. [...] No preço da pensão de $120 \$ 000$ por trimestre comprehende-se o ensino da doutrina christã, princípios de civilidade e polidez, línguas portugueza, franceza e ingleza, caligraphia, arithmetica, historia universal e a especial do Brasil, geographia, physica e astronômica, todos os trabalhos de agulha, bordados e flores de todas as qualidades. (Almanak Laemmert, 1872, p. 458)

Além da questão religiosa, havia uma grande ênfase à educação moral, tão valorizada nos colégios de maneira geral, como também no Imperial Instituto dos Surdos-Mudos. Leite (1871), no mesmo relatório mencionado anteriormente, destaca a situação que os surdos educados no Instituto apresentavam em relação ao comportamento:

É satisfatório o estado dos alumnos n'este importantissimo ramo da educação, não só porque nenhum facto se deu que revelasse perversão de sentimentos, ou corrupção de costumes, como a esquivança, a irritabilidade e a desconfiança, tão naturaes no surdo-mudo, desappareceram, e hoje os que visitam o Instituto nas horas dos recreios ficam surprehendidos vendo que entre os alumnos reinam a ruidosa alegria, a mobilidade e a expansão que se observam nos recreios dos collegios dos fallantes. Contudo este estado ainda não me satisfaz, porque ainda não basta: eu desejaria infundir n'esses infelizes todos os sentimentos nobres e ideias magnanimas, que devem adornar o coração e illustrar a intelligencia da nossa mocidade, falta-me porém um auxiliar mais idôneo do que o Inspector de alumnos que o Regulamento creou. A brandura, a persuasão, a affabilidade acompanhadas de inesgotavel paciência, e apoiadas na mais escrupulosa pureza de costumes, são os únicos e infalliveis meios de captar a confiança do surdo-mudo, e de amolda-lo com a mesma facilidade com que se faz o que se deseja da cera aquecida entre os dedos. (Leite, 1871, p. 6)

No relatório de Tobias Leite, vemos uma grande preocupação com a educação moral, fato comumente encontrado à época em outros estabelecimentos educativos, conforme já citado. 


\section{A ICONOGRAPHIA DOS SIGNAES DOS SURDOS-MUDOS}

Importa saber que Tobias Leite apoiou Flausino na iniciativa de elaborar a obra Iconographia dos Signaes dos Surdos-Mudos, pois a edição de uma obra dessa natureza daria visibilidade ao trabalho desenvolvido no Instituto e nada melhor que um aluno, educado nesse estabelecimento, no papel de autor/produtor. A obra estruturava-se de forma semelhante a um dicionário.

A obra de Flausino constitui-se basicamente de 382 estampas, compostas por imagens referentes aos sinais que foram escolhidos para compor o léxico e, também pelos verbetes em Língua Portuguesa correspondentes ao significado desses mesmos sinais. No prefácio da Iconographia dos Signaes dos Surdos-Mudos, escrito pelo próprio diretor Tobias Leite, encontramos as finalidades atribuídas a sua existência; entre elas, destacamos: a intenção de "vulgarizar a linguagem dos signaes, meio predilecto dos surdos-mudos para a manifestação de seus pensamentos e mostrar o quanto deve ser apreciado um surdo-mudo educado" (Leite apud Gama, 1875).

A questão que se coloca é: como ocorreu a criação da obra de Flausino da Gama?

Leite destaca que Flausino da Gama, vendo entre os livros da biblioteca do Instituto "a obra do ilustre surdo-mudo Pélissier, professor do Instituto de Paris, manifestou o desejo de reproduzir as estampas para os falantes conversarem com os surdos-mudos". Ao que tudo indica, Flausino foi muito insistente em seu pedido.

Além de ser um exímio repetidor, no prefácio é declarado que ele era um hábil desenhista, e o que inviabilizava a execução de seu desejo era a falta de recursos financeiros do Instituto, pois as despesas com o mesmo eram grandes. Tobias Leite comunicou o fato ao Sr. Eduard Rensburg, dono de oficina de litografia na época, o qual, após tomar conhecimento da situação, se ofereceu para ensinar a Flausino o desenho litográfico, colocando a sua oficina à disposição para a concretização da obra. O diretor de Flausino aceitou prontamente a proposta, e, segundo ele, "em poucos dias sahio o livro que tenho a satisfacção de apresentar a todos os que se interessarem por essa numerosa classe de nossos compatriottas" (Leite, 1875 apud Gama, 1875 ).

O livro de Flausino foi impresso em 1875, de acordo com Gama (1875), embora em muitas referências encontremos a data equivocada de 1873. Sua divulgação foi promovida de forma tão eficaz que até nos dias atuais sabemos de sua existência, apesar dos poucos exemplares que sobreviveram em circulação. Não menosprezando a sua importância em termos históricos, culturais e linguísticos, podemos inferir que, por meio da elaboração e concretização dessa obra, se criou um mito na história da origem da língua brasileira de sinais acerca de Flausino e da sua produção.

\section{A CONSTRUÇÃO DE UM MITO ACERCA DE FLAUSINO DA GAMA}

De acordo com Chaui (2003, p. 35), o mito é uma narrativa sobre a origem de alguma coisa. "A palavra mito vem do grego, mythos, e deriva de dois verbos: 
do verbo mythero (contar, narrar, falar alguma coisa para os outros) e do verbo mytheo (conversar, contar, anunciar, nomear, designar)". Para explicar a composição de um mito, a autora recorre a Lévi-Strauss, que se refere a uma atividade que existe em nossa sociedade e que, em francês, se chama bricolage. Nessa ótica, a pessoa que pratica bricolage produz um objeto novo a partir de pedaços e fragmentos de outros objetos existentes. Vai reunindo sem um plano muito rígido tudo o que encontra e que serve para o objeto que está compondo. O pensamento mítico tem essas mesmas características, pois vai reunindo as experiências, as narrativas, os relatos, até compor um mito geral. E, por meio desses materiais heterogêneos, produz a explicação sobre a origem e a forma das coisas, suas funções e também finalidades.

Isso ocorreu dentro da história brasileira da surdez, no que se refere ao surgimento do primeiro material impresso de língua de sinais e da pessoa de Flausino. O fato da publicação é real, mas o pioneirismo é mito, já que a obra não pode ser considerada original, visto que Flausino a reproduziu fielmente com base num exemplar francês. Para o contexto da época em que foi criado isso era comum, embora já existissem previsões em lei acerca de plágio. Muitas pessoas envolvidas com a área da surdez, por não estudarem de forma mais aprofundada o fato e suas implicações, acabaram propagando esse mito, que acabou tornando-se um "mito geral".

Na revisão bibliográfica que realizamos, não encontramos nenhum autor que suscitasse um questionamento a respeito da "história oficial" que envolve Flausino e seu trabalho. Os relatos a respeito de sua trajetória e sua realização são muito próximos:

Flausino José da Gama era aluno do Instituto Nacional dos Surdos-Mudos (hoje Instituto Nacional de Educação de Surdos - ou INES) quando, inspirado no livro do surdo francês Pellisier na biblioteca do INES, publicou em 1873, o livro Iconographia dos Signaes dos Surdos-Mudos, de que há somente uma edição original na Biblioteca Nacional e cópia em microfilmes disponíveis na biblioteca do INES. (Capovilla; Rafael, 2004, p. 14)

Contrariando a citação anterior, é necessário ressaltar que existem algumas cópias impressas da Iconographia dos Signaes dos Surdos-Mudos na Biblioteca Nacional no Rio de Janeiro, não existindo, portanto, atualmente, somente uma edição original. $O$ fato é que existem quatro cópias impressas desse material na referida biblioteca, porém três delas se encontram incompletas e danificadas em virtude da má conservação e do mau uso. Somente uma está completa, contudo também apresenta sinais de conservação inadequada. Entretanto, não sabemos precisar o número de cópias que foram impressas a partir das pedras litográficas produzidas por Flausino.

Muitas pessoas envolvidas com a área da surdez, ao que parece, tiveram um contato superficial com a Iconographia dos Signaes dos Surdos-Mudos; por esse motivo, circulam na área da surdez e da língua brasileira de sinais muitos equívocos, valorizando a obra como original: 
É de 1873 a publicação do mais importante documento encontrado até hoje sobre a língua brasileira de sinais, o Iconographia dos Signaes dos Surdos-Mudos, de autoria do aluno surdo Flausino José da Gama, com ilustrações de sinais separados por categorias (animais, objetos etc.). Como é explicado no prefácio do livro, a inspiração para o trabalho veio de um livro publicado na França e que se encontrava à disposição dos alunos na biblioteca do INSM. Vale ressaltar que Flausino foi autor das ilustrações e da própria impressão em técnica de litografia. Não sabemos se a organização também foi realizada por ele. (Ramos, s.d, p. 6)

As referências ao trabalho desse surdo repetidor também são devidas ao caráter pioneiro que ele aparenta ter, a exemplo disso:

Flausino José da Gama, na segunda metade do XIX, andou desenhando. Era aluno do Imperial Instituto de Surdos-Mudos. Ainda mudo. Mudez entendida como incapacidade de se expressar. No entanto, em 1873, desenhou as primeiras ilustrações do primeiro dicionário de língua de sinais de que se tem notícia no Brasil, chamado Iconographia dos Signaes dos Surdos-Mudos. [...] Quase dois séculos depois, outros surdos enlaçados com ouvintes perseguem o rastro de Flausino. (Rocha, 2004, p. 14 apud Capovilla; Rafael, 2004, p. 14)

É importante ressaltar que Flausino não buscou “inspiração" no livro de Pélissier e sim copiou ipsis litteris suas estampas para produzir a Iconographia dos Signaes dos Surdos-Mudos. Porém, nessa época em que a popularização da imagem se fazia presente, a cópia não tinha a mesma conotação dos dias atuais. No contexto do século XIX, no que tange à Arte, a reprodução tinha outra interpretação, sendo considerada essencial na definição neoclássica: não se tratava apenas de copiar, mas de buscar inspiração. Assim sendo, o ato de reproduzir estava inserido num processo contínuo de aprendizagem. Nessa perspectiva, a prática da cópia ganhou um novo estatuto e assumiu um papel fundamental na formação básica e desenvolvimento dos artistas que faziam parte desse processo.

Nesse sentido, a criação litográfica na época era marcada pela:

Imagem reprodutível e múltipla, de execução mais acessível do que a gravura em metal, o desenho na pedra litográfica podia oferecer grande apelo estético, além de representar um convite às transcrições, cópias e adaptações que, na cultura visual do século XIX, promoviam "releituras" do mundo visível pelas diferentes formas de representação iconográficas então existentes. (Turazzi, 2009, p. 59)

Assim sendo, o ato de copiar, em se tratando de atividade artística, era considerado de certa forma "natural", entretanto não era isso que estava previsto no Codigo Criminal do Imperio do Brazil, instituído em 16 de dezembro de 1830. 
Hallewell (1985, p. 171) declara que o artigo 261 do Código Criminal do Império rezava que era crime "imprimir, gravar, litographar ou introduzir quaesquer escriptos ou estampas que tiverem sido feitos, compostos ou traduzidos por cidadãos brazileiros enquanto estes viverem e dez annos depois de sua morte si deixarem herdeiros”. Entretanto, o mesmo autor destaca que essa previsão não passava de letra morta, pois a verdadeira lei de direitos autorais no Brasil surgiu em 1898. Apesar desse fato, era difundida na sociedade da época a repulsa moral a quem praticasse "esse tipo de pirataria" em território nacional, além da "vaga impressão" de que os plagiadores poderiam ser processados segundo os princípios gerais da lei de propriedade. Se o referido Código não passava de "letra morta", de acordo com as palavras do autor citado, talvez por esse motivo Flausino tenha considerado natural reproduzir a obra de Pierre Pélissier.

A ausência de pesquisas nessa área faz que as mesmas fontes sejam utilizadas continuamente. A falta de pesquisa em documentos primários na academia pode resultar em equívocos, como se vê na citação a seguir:

[...] foi do então Instituto dos Surdos-Mudos do Rio de Janeiro, hoje Instituto Nacional de Educação de Surdos (INES), que saíram os principais divulgadores da LIBRAS. A iconografia dos sinais - ou seja, a criação dos símbolos, só foi apresentada em 1873, pelo aluno Flausino da Gama. Ela é resultado da mistura da Língua de Sinais Francesa com a Língua de Sinais Brasileira antiga, já usada pelos surdos das várias regiões do Brasil. (Menezes, 2006 apud Silva, s.d., p. 136)

$\mathrm{Na}$ citação anterior, podemos observar uma série de problemas em relação ao uso de conceitos e exposição de fatos relacionados à história da educação do surdo no Brasil. O termo iconografia é utilizado erroneamente como sinônimo de criação de símbolos. Por tratar-se de um conceito "polissêmico", assim como tantos outros, a utilização dessa terminologia deve ser cuidadosa. Para Turazzi (2009), o termo iconografia:

Compreende tanto a(s) arte (s) e a técnica de representação através da imagem, quanto a própria documentação (um conjunto de imagens) resultantes dessa atividade e, por extensão, a área do conhecimento voltada para a descrição e a interpretação de tais representações, hoje objeto de estudo de diversas disciplinas (história da arte, antropologia visual, história da ciência etc.). Cada sentido da palavra está, de certa forma, imbricado no outro e em todos eles o uso do vocábulo liga-se, indissoluvelmente, à construção do conhecimento e da memória em suportes visuais, bem como à sua transformação em objeto de estudo para a história. (Turazzi, 2009, p. 50)

A autora ainda refere que, dependendo do uso que se faça da palavra iconografia, ele exige um esforço de circunscrição do seu campo de abrangência e significação. Pelo que pudemos observar, o uso desse termo é muitas vezes 
indiscriminado ou até mesmo desconhecido por pessoas que estudam a área da surdez, fazendo que o utilizem de forma inadequada. Outro problema encontrado na citação de Menezes (2006, apud Silva, s.d, p.136) refere-se à suposta origem da iconografia apresentada por Flausino da Gama em seu dicionário. Os sinais apresentados na obra são os mesmos encontrados no dicionário do surdo francês Pierre Pélissier; portanto não são uma "mistura da língua francesa de sinais com a língua brasileira antiga”, mas sinais da língua francesa de sinais. Como no Brasil não existia nenhum dicionário de língua de sinais ou outro material similar, Flausino propôs, por meio do material que elaborou, empregando sinais franceses como se fossem brasileiros, a criação de uma língua de sinais "originalmente" brasileira.

Ainda no que tange ao uso inadequado de terminologias e conceituações, apresentamos o relato a seguir:

Em 1875 o diretor do então chamado Instituto dos Surdos-Mudos (atual INES/ Instituto Nacional de Educação de Surdos), Tobias Leite, fez publicar a Iconografia dos Sinais dos Surdos-Mudos, de autoria do ex-aluno Flausino José da Costa Gama, que trabalhava na instituição como repetidor (instrutor em língua de sinais) desde 1871 e onde permaneceu até 1879. (Editora Arara Azul, 2010)

A citação mencionada indica que Flausino era repetidor. E a seguir apresenta entre parênteses o que significa tal conceito. Por meio desse estudo, pudemos verificar que a função de repetidor era muito mais abrangente que um "mero" instrutor de língua de sinais. Ademais, na época de Flausino, o ensino de língua de sinais não estava previsto no currículo do Instituto; se ela era propagada dentro da instituição, isso se dava de maneira informal, na comunicação entre surdos usuários também desse tipo de língua. Além do fato mencionado, consta na citação anterior outro equívoco: Flausino, de acordo com os registros históricos encontrados no Almanak, encerrou as suas atividades como repetidor em 1878 e não em 1879, como apresenta a referida citação.

Também pudemos detectar problemas na literatura da área no que se refere à forma como o material de Flausino foi elaborado:

Aqui no Brasil, há mais de cem anos, a primeira escola para surdos valorizava a LIBRAS, que era utilizada pelos alunos naquela época. Este respeito à LIBRAS propiciou o surgimento da primeira pesquisa sobre esta língua, que foi publicada em um livro que, através de desenhos e explicações destes, mostrava sinais mais usados pela comunidade surda do Rio de Janeiro. Este livro, Iconografia dos Signaes dos Surdos-Mudos publicado em 1875, foi feito por um ex-aluno do Instituto de Surdos-Mudos, Flausino da Gama que, ao completar dezoito anos, foi contratado por esta escola para ser um repetidor. (Felipe, 2001, p. 139) 
Como já mencionado anteriormente, a Iconographia dos Signaes dos Surdos-Mudos foi fruto de um trabalho de reprodução de Flausino da Gama a partir de uma obra datada de 1856 . Nesse sentido, não houve uma pesquisa por parte do autor para a elaboração do material, mas uma apropriação de algo já existente. Flausino, de acordo com pesquisas realizadas, quando elaborou a sua obra, não era ex-aluno do Instituto e sim aluno regular e também repetidor. No que se refere a essa função, ele iniciou as suas atividades em 1871, aos 20 anos. A citação aponta que ele foi contratado pela "escola" para ser repetidor. Naquela época, o repetidor era escolhido pelo seu desempenho acadêmico, não sendo, portanto, contratado.

O nosso intuito não é negar a importância da iniciativa de Flausino e seu empenho em empreender um material brasileiro, mas buscar subsídios para discutir a produção no contexto próprio de seu tempo. O fato de Flausino ter se inspirado na obra de um surdo francês, da forma como foi escrito, sugere a interpretação de que, ao ter contato com o material do colega surdo, teve a ideia de também desenhar, baseado em sinais brasileiros.

Porém, ao ter contato com o material produzido por Pélissier, constatamos que não foi isso que ocorreu. A organização do dicionário de Flausino, no que diz respeito à forma de indexar o léxico, a constituição das imagens e os verbetes correspondentes às mesmas, é idêntica à do dicionário de Pélissier. É evidente que Flausino copiou a obra de Pélissier, prancha por prancha, em termos de visualidade, e supostamente traduziu os verbetes escritos em francês para a língua portuguesa, já que não consta o nome do tradutor na obra. E, a partir de então, tornou-se o "precursor" de uma iconografia da língua brasileira de sinais.

Não obstante os problemas apontados ao longo deste trabalho, inferimos que talvez, ao realizar esse trabalho, Flausino tenha tido uma grande motivação: reproduzir uma obra para alargar um conhecimento que dizia respeito a uma língua, extremamente necessária para a comunicação entre surdos e ouvintes.

\section{CONSIDERAÇÕES FINAIS}

Os estudos sobre a fundação do Imperial Instituto dos Surdos-Mudos e sobre a gestão do diretor Tobias Leite permitiram descortinar alguns poucos fatos sobre a vida de Flausino da Gama na época em que foi repetidor. Tratava-se de realidade bastante dura, que obrigava os próprios alunos a assumirem postos de trabalho que deveriam ser ocupados por pessoas designadas pelo Estado. Pudemos comprovar esse fato pelas declarações do diretor Tobias Leite em seus relatórios de 1869 e 1871. Além da falta de funcionários para o exercício das funções existentes no Instituto, vislumbramos também a falta de preparo dos que se encontravam ali para lidar com alunos surdos. 
De qualquer maneira, o "protagonismo", pelo menos aparente, vivido por Flausino, é que o levou a realizar o seu intento. $\mathrm{O}$ fato de um surdo produzir um material sobre língua de sinais, mesmo tendo outro surdo como inspiração, é algo a se considerar, porque, historicamente, muitos dicionários de línguas de sinais foram produzidos por ouvintes. Tanto foi importante que, por meio de sua iniciativa, outros materiais foram surgindo e apresentando-se de forma semelhante, ou seja, Flausino acabou instituindo uma tradição iconográfica para a língua brasileira de sinais, servindo de referência para os ilustradores com a incumbência de ilustrar materiais dessa natureza. E até os dias atuais encontramos dicionários de línguas de sinais com as mesmas características relativas à visualidade e composição das imagens observadas na obra de Flausino.

Este estudo permitiu verificar que Flausino não foi o criador de uma iconografia, mas o "repetidor" de uma já existente; o seu processo é marcado pela reprodução de algo já consolidado, e não pela criação de algo inusitado. Entretanto, a concepção que se tem a respeito de direito autoral atualmente, ou melhor, da prática da cópia, é diferente da que se tinha no século XIX.

Chega a ser paradoxal o tratamento dado à prática da cópia no século XIX: ao mesmo tempo em que teve origem no neoclássico, sendo, portanto, legitimada como produção artística, era também descrita em lei como atitude de má-fé. Ao que parece, Flausino e seus responsáveis desconheciam as implicações legais que o ato de copiar poderia acarretar, tanto que, além de copiar os desenhos de Pélissier, Flausino ainda traduziu os verbetes da língua francesa para a língua portuguesa na composição da sua obra. Lembramos que o objetivo primeiro da proposta era "vulgarisar [significando popularizar, democratizar o acesso] a linguagem de signaes, meio predilecto dos surdos-mudos para a manifestação dos seus pensamentos" (Gama, 1875).

Constatamos que a elaboração da Iconographia dos Signaes dos Surdos-Mudos, por Flausino da Gama, transformou-o num mito da história da surdez e da língua de sinais. Como foi o precursor na elaboração de uma obra pioneira, muitas pessoas da área valorizam a iniciativa, porém desconhecem realmente $o$ que Flausino fez. A reprodução do material de Pélissier foi realizada com base nos conhecimentos que possuía de desenho; talvez, no Imperial Instituto dos Surdos-Mudos, as aulas relativas a essa disciplina tenham lhe proporcionado algumas noções da técnica.

Esperamos que, por meio do presente trabalho, tenhamos auxiliado a elucidar conhecimentos sobre a trajetória educacional de Flausino e sua obra, contribuindo para apresentar Flausino à comunidade científica como um surdo que teve importante papel na propagação da língua brasileira de sinais, com a primeira tentativa de registro há 136 anos. 


\section{REFERÊNCIAS}

Almanak Laemmert. In: Center for Research Libraries: Global Resources Network [1844-1889], 1874. Disponível em: <http://www.crl.edu/brazil/almanak>. Acesso em: 13 fev 2011.

Capovilla, Fernando C.; Rafael, Walkiria D. Enciclopédia da lingua de sinais brasileira: o mundo do surdo em LIBRAS. São Paulo: Fundação Vitae; FAPESP; EDUSP; Imprensa Oficial do Estado de São Paulo, 2004.

Chaur, Marilena. Convite à filosofia. São Paulo: Ática, 2003.

EDitora Arara Azul. Disponível em: http://editora-arara-azul.com.br/novoeaa/ dicionario-de-lingua-de-sinais-de-1875/. Acesso em: 11 dez. 2011.

FELIPE, Tanya A. LIBRAS em contexto: curso básico-programa nacional de apoio à educação de surdos. Brasília: MEC, SEESP, 2001.

Gama, Flausino José da. Iconographia dos signaes dos surdos-mudos. Rio de Janeiro: Tipografia Universal de E. \& H. Laemmert, 1875.

GiL, Antônio Carlos. Como elaborar projetos de pesquisa. São Paulo: Atlas, 1991.

Hallewell, Laurence. O livro no Brasil: sua história. Tradução de Maria da Penha Villalobos e Lólio Lourenço de Oliveira. São Paulo: T. A. Queiroz; EDUSP, 1985.

Jannuzzi, Gilberta S. de M. A educação do deficiente no Brasil: dos primórdios ao início do século XIX. Campinas: Autores Associados, 2004.

LeITE, Tobias Rabelo. Instituto dos Surdos-Mudos: relatório do director. Rio de Janeiro, 1869.

. Instituto dos Surdos-Mudos: relatório do director. Rio de Janeiro, 1871.

Neves, Fátima Maria. Método de Lancaster ou método lancasteriano. 2003. Disponível em: <http://www.histedbr.fae.unicamp.br/...verb_c_metodo_lancaster>. Acesso em: 28 dez. 2010.

Ramos, Clélia Regina. LIBRAS: a língua de sinais dos surdos brasileiros. [s.d]. Disponível em <http://www.editora-arara-azul.com.br>. Acesso em: 11 out. 2009.

RocHA, Solange. O INES e a educação de surdos no Brasil: aspectos da trajetória do Instituto Nacional de Educação de Surdos em seu percurso de 150 anos. Rio de Janeiro: INES, 2007.

SILVA, Cleusiane Vieira. LIBRAS e linguagem matemática: particularidades afins para um novo estudo inclusivo. [s.d]. Disponível em: <www.sbemba.com.br/anais_ do_forum>. Acesso em: 11 out. 2009.

TurAzZI, Maria Inez. Iconografia e patrimônio: o catálogo da exposição de história do Brasil e a fisionomia da nação. Rio de Janeiro: Biblioteca Nacional, 2009. 


\section{SOBRE AS AUTORAS}

Cássia Geciauskas Sofiato é doutora em artes pela Universidade Estadual de Campinas (UNICAMP). Professora da Pontifícia Universidade Católica de Campinas (PUC-Campinas).

E-mail: cassiasofiato@gmail.com

LuCia HELENA ReiLY é doutora em psicologia escolar e do desenvolvimento humano pela Universidade de São Paulo (USP). Professora da Universidade Estadual de Campinas (UNICAMP).

E-mail: lureily@terra.com.br

Recebido em agosto de 2011 Aprovado em setembro de 2011 
much more complex than a simple question of maintaining inequalities. It affirms that courses allow offering students reliable knowledge. The paper concludes that although global trends may foresee changes in occupations, it cannot be presumed that they apply to production or acquisition of reliable knowledge.

Keywords: education; curriculum; knowledge; course content.

\section{El futuro de la educación en una sociedad del conocimiento: el argumento radical en defensa de un currículo centrado en diciplinas}

El texto focaliza el papel, en la educación, del conocimiento en sí. Argumenta que, para darse un sentido serio a la importancia de la educación, es fundamental tornar la cuestión del conocimiento en foco central del análisis en el campo de la educación, lo que requiere el desarrollo de un abordaje del currículo fundamentado más en el conocimiento y en la disciplina y menos en el aprendiz y en sus intereses. Defiende, todavia, que esa es una opción radical. El articulo sustenta que, en términos curriculares, no hay ninguna alternativa a las disciplinas que se muestren adecuadas y que definan los conocimientos que los alumnos deben adquirir. Asegura, todavía, que el papel de las escuelas y del currículo centrado en disciplinas es bien más complejo de lo que simplemente mantener desigualdades. Afirma que las disciplinas permiten que se ofrezca a los alumnos un conocimiento confiable. Por fin, considera que aunque las tendencias globales puedan prever mudanzas en las ocupaciones, no se puede presumir que ellas se apliquen a la producción o a la adquisición del conocimiento confiable.

Palabras clave: educación; currículo; conocimiento; disciplina.

\section{CÁSSIA GECIAUSKAS SOFIATO E LUCIA HELENA REILY}

\section{“Companheiros de infortúnio": a educação de "surdos-mudos” e o repetidor Flausino da Gama}

Este trabalho tem como objetivo apresentar a trajetória educacional de Flausino José da Costa Gama, aluno do Imperial Instituto dos Surdos-Mudos do Rio de Janeiro no século XIX. Flausino, além de ter sido um aluno e "repetidor" exemplar, segundo registros da época, destacou-se também pela criação da primeira obra de língua de sinais de que se tem notícia no Brasil: a Iconographia dos Signaes dos Surdos-Mudos, em 1875. Por meio de uma pesquisa bibliográfica e documental, apresentamos a proposta pedagógica do Imperial Instituto dos Surdos-Mudos e seus objetivos educacionais à época em que o diretor era o Dr. Tobias Leite e evidenciamos o percurso educacional de Flausino, primeiramente trazendo a sua biografia e todo o seu desenvolvimento a partir do ingresso na referida instituição. Além disso, destacamos o contexto no qual 
se deu a criação da primeira obra de língua de sinais do Brasil, obra realizada por meio de litografia, formada por vinte estampas que apresentam 382 sinais, excetuando-se o alfabeto manual. Com este estudo pretendemos apresentar Flausino à comunidade acadêmica como um surdo que teve um percurso educacional diferenciado e que contribuiu de forma muito relevante para a origem da língua brasileira de sinais.

Palavras-chave: educação especial; história da educação; surdez; iconografia.

\section{"Companions in misfortune": education of "deaf-mutes" and the Flausino da Gama, a lesson repeater}

The aim of this study is to present the educational trajectory of Flausino Jose da Costa Gama, who was a student at the Imperial Institute for Deaf-Mutes of Rio de Janeiro in the nineteenth-century. Besides having been an exemplary student and "lesson repeater", according to records of the times, he distinguished bimself by creating the first sign language to date in Brazil, i.e. the Iconography of Signs of Deaf-Mutes of 1875. Using bibliographic and documentary research, we present the pedagogical proposal used at the Imperial Institute for Deaf-Mutes. The study discusses the institution's educational objectives at the time when Dr. Tobias Leite was headmaster and presents Flausino's educational trajectory based on biographical data and on his development upon enrollment in said institution. An understanding of the social and cultural context of the times aids in understanding the process that led to the creation of the first Brazilian sign language publication; besides a page containing the manual alphabet, the book boasts 20 printed images of 382 manual signs using lithography. We hope to present Flausino to the academic community as a deaf person whose educational pathway was unique, and who contributed in a relevant way to the beginnings of Brazilian sign language

Keywords: special education; history of education; deafness; iconography.

\section{"Compañeros de infortunio": la educación de "sordos-mudos" y el repetidor Flausino da Gama}

Este trabajo tiene como objetivo presentar la trayectoria educacional de Flausino José da Costa Gama, alumno del Imperial Instituto de los Sordos-Mudos de Rio de Janeiro en el siglo XIX. Flausino, más allá de tener sido alumno y "repetidor" ejemplar, según registros de la época, ha se destacado también por la creación de la primera producción de lengua de señales que se conoce en Brasil: la Iconographia dos Signaes dos Surdos-Mudos en 1875. Por medio de una investigación bibliográfica y documental, presentamos la propuesta pedagógica del Imperial Instituto de los Sordos-Mudos y sus objetivos educacionales cuando el Dr. Tobias Leite era director y mostramos el recorrido educacional de Flausino, trayendo antes su biografía y su desarrollo a partir del ingreso en la institución referida. Además, destacamos el contexto en lo cual se dio la creación del primer trabajo brasileño de lengua de señales, producido en litografia, formada por 20 estampas que presentan 382 señales, y también el alfabeto manual. Con este estudio, pretendemos mostrar a la 
comunidad académica quien fue Flausino, un sordo que tuvo un recorrido diferenciado y que contribuyó de manera relevante para la origen de la lengua de señales brasileña.

Palabras clave: educación especial; historia de la educación; sordera; iconografia.

\section{ANA CANEN E GISELI PERELI DE MOURA XAVIER}

\section{Formação continuada de professores para a diversidade cultural: ênfases, silêncios e perspectivas}

A formação continuada de professores tem sido objeto de debates nos contextos acadêmicos e políticos. $\mathrm{O}$ artigo sugere uma perspectiva "culturalmente responsiva" como caminho promissor para essa formação, analisando, a partir desse olhar, a produção do conhecimento na área, no presente milênio, por intermédio da análise documental de dois periódicos classificados como internacionais pelo sistema Qualis/CAPES, mais especificamente, Cadernos de Pesquisa e Revista Brasileira de Educação, bem como de trabalhos apresentados nas reuniões anuais da Associação Nacional de Pós-Graduação e Pesquisa em Educação (ANPEd), com foco nos GTs de Formação de Professores, Didática, Educação e Relações Étnico-Raciais e Gênero, Sexualidade e Educação. Os dados oferecem um panorama da temática na produção acadêmica, problematizando silêncios e apontando potenciais e desafios, podendo contribuir para se pensar em formas plurais pelas quais a formação docente para a diversidade cultural pode se desenvolver.

Palavras-chave: formação continuada de professores; diversidade cultural; multiculturalismo; produção do conhecimento.

\section{Continuing teacher education for cultural diversity: emphases, silences and perspectives}

Teacher continuing education has been the focus of debates in political and academic contexts. The present paper suggests a "culturally responsive" perspective as a promising way towards that education, and it discusses the knowledge production in the area during the present millennium, through documentary analysis of two Brazilian scientific journals classified as international, as well as of studies presented in the annual meetings of the ANPEd (the Brazilian National Association of Post-Graduation and Research in Education), focusing on its working groups that deal with Teacher Education, Didactics, Education and Ethnic and Racial Relations, and Gender, Sexuality and Education. The data convey an overview of that production, problematising silences, as well as pointing to potentials and challenges of that production. Its relevance comes insofar as it can contribute to thinking about plural ways through which teacher education for cultural diversity may develop.

Keywords: teacher continuing education; cultural diversity; multiculturalism; knowledge production. 